\title{
Research on the Classification of Historical and Cultural Resources in China
}

\author{
YU-XI HUANG ${ }^{1, a,{ }^{,}, R u n-D e ~ L U}{ }^{2, b}$ \\ ${ }^{1}$ Business school, Guilin University of Electronic Technology, Guilin 541004, \\ Guangxi province, China \\ ${ }^{2}$ Business school, Guilin University of Electronic Technology, Guilin 541004, \\ Guangxi province, China \\ ae-mail:hyxtop@qq.com, be-mail: 2690817809@qq.com
}

Key words: Classification of historical and cultural resources, Study summary, Construction of a new classification system, Four-level classification

\begin{abstract}
The article clearly points out that the classification of historical and cultural resources plays a significant role in protecting, developing, and utilizing historical and cultural resources. Based on related resource-allocation theory and many domestic scholars' view on the case study of the classification of historical and cultural resources, the article integrates and extends the existing classification of historical and cultural resources, which in turn establishes a new system on the classification of historical and cultural resources.
\end{abstract}

\section{Introduction}

Historical and cultural resources are the things that affect humans occurred in the past and become the spiritual needs of the mental element attached to the material. It is the sum of human creation and use of a variety of material and cultural resources and spiritual and cultural resources. It is a unique feature of modern asset value, historical and cultural relics that can be exploitable [1]. Our civilization has a history of five thousand years, there remains a lot of, a great variety of valuable historical and cultural resources. To carry out the study of historical and cultural classification is not only the need of a comprehensive and profound understanding of the history and culture of our country, but also the basis of scientific and accurate assessment of the value of all kinds of historical and cultural resources. For effective protection and rational exploitation and utilization of the historical and cultural resources of our country, strengthen cultural industry of our country has extremely significant significance.

\section{Summary of Theoretical Research and Practice}

\section{The Situation of Domestic Scholars}

Dan Zeng (2006) considered[2], from the form of cultural resources can be divided into material and cultural resources and spiritual and cultural resources, or called tangible cultural resources (such as historical relics sites, characteristics of residential buildings, historical and cultural cities, towns, specialty apparel, folk crafts, etc.) and intangible cultural resources (such as languages, literature and art, painting art, music, dance, myths and legends, customs, ethnic festivals, etc.). From the content, cultural resources can be divided into historical and cultural resources, ethnically cultural resources, religious and cultural resources, geographical and cultural resources (such as urban culture, rural culture) and so on. From the perspective of the development of cultural industries, it can be divided into the cultural resources that can be developed and cannot be developed.

He Suwen (2007) classified historical and cultural resources into production and lifestyle, social management and ideological three categories based on the tourism resources classification of induction, comparison, and summary [3]. 
Zhang Weixing, AI Pei (2007)[4], comparing with the history and culture, from the aspects of the connotation of resources, historical and cultural resources can be divided into three levels, namely the material level, the ideological system, cultural psychological layer.

Li Dahua, Zhou Cuiling (2008) considered[5], through the integration of local shape with the overall style of resources, historical and cultural resources are divided into the following categories: ecological landscape, historical and cultural heritage, Shangdu culture, architectural features, folk customs and technology, modern city, historical and cultural resources of celebrity culture.

Wu Ming, Wang YongHui(2009) considered[6], according to the history of the formation and function and characteristics of the national culture and function characteristics, historical and cultural resources can be divided into the following categories: ancient capital, regional government center, a few characteristics of the national culture, to commemorate the resort and ancient city traffic and handicraft industry, mining developed industry.

HaoShuaishuai (2010) considered[7], in order to better distinguish the modern resources and historical and cultural resources, need to add "traditional" or "historical" word on the category name, the historical and cultural resources are divided into relics, building facilities, artifacts and historical and cultural activities.

Ran Jingjing(2010) starting from the perspective of heritage protection, in referring to the various current domestic and foreign conservation regulations, historical and cultural resources are divided into complex resource, cultural relics, non material and cultural resources and natural and cultural resources[8].

Zhao Dong(2014) combined the four basic elements of historical and cultural resources of the things, people, time, place, which was classified as historical events and cultural resources, history of physical (relics, ancient books, etc.) and cultural resources, historical figures (usually celebrities) cultural resources, the original cultural resources, cultural resources of ancient, modern and contemporary cultural resources. While the local historical and cultural resources are divided into: $\mathrm{Wu}$ Yue cultural resources, cultural resources of the Central Plains, Bashucultural resources, Qilu cultural resources; or directly at the current domestic provinces divided into historical and cultural resources of Shanxi, Sichuan, Shandong historical and cultural resources and so on[9].

\section{Countries and Industry Related Classification}

Country and industry on resources classification standards are: Classification, investigation and evaluation of tourism resources(GB/T 18972-2003)[10];Regulations for protection of historical and cultural city (GB50357-2005)[11]; Historical and cultural city town village protection ordinance[12]; The historical and cultural city town village protection planning requirements (Trial)[13]; The cultural relics protection law of the people's republic of China[14];Convention on the protection of the word cultural and natural heritage[15]; Convention on the protection of intangible cultural heritage[16];National intangible cultural heritage list[17].

\section{Commentary}

At present, the academic study of historical and cultural resources focused on defining its concept and the classification of intangible cultural heritage, and classification of historical and cultural resources of the movable and immovable cultural relics are clearly insufficient. Research focuses on how to divide it into several categories, rarely involved in the detailed division of its basic types, classification is too general,study time is also concentrated in the past 2010. Some of the existing classification although covers most of the historical and cultural resources, but there are also such as lack of type, type cross repetition and function and time division standard mixed. The basic elements of historical and cultural resources are closely linked and cannot be simply divided, so that it is difficult to make a complete division between the various types of historical and cultural resources. Of course, many scholars according to various classification of historical and cultural resources in the long and useful research, but because of the diversity of resources and different resources between incomparability determines any classification cannot cover all types of resources. Moreover, due to the non uniqueness of the classification principle, the different classification results can not compatible. At present, the most complete classification is only to level three. In 
addition, the country and the industry has not yet introduced a unified classification of historical and cultural resources standards.

\section{Research Methods and Data Sources}

\section{Construction Based on Historical and Cultural Resources of New Classification System The Views of Scholars with Country and Industry Relevant Documents}

In general, the classification is based on external features or essential features of things classified. For example, Classification, investigation and evaluation of tourism resources (GB / $\mathrm{T}$ 18972-2003)[10] is based on characters of tourism resources, namely the existing situation, morphology, properties and characteristics of division. GB tourism resources are divided into 8 categories, of which the first four belong to the category of natural and cultural resources, andthe second four is the category of human resources. In this paper, the historical and cultural resources are part of the humanities tourism resources, concentrated in the second four categories of resources in the GB. Ding Jihua in thetourism resources[18]thought the humanities tourism resources can divided into historical and cultural city, historical sites, religious culture, architecture and landscape, literature and art and transportation and tourism resources of the six categories. In Survey specification of China's tourism resources(1992)[19]the cultural tourism resources are mainly divided into ruins, buildings and facilities, tourism commodities, cultural activities. Chinese tourism geography [20]edited by Luo Zibai ,Zhang Shulin the cultural tourism resources are divided into three categories, such as historic sites and buildings, leisure knowledge and fitness, and shopping.

UNESCO adopted the Convention on the protection of the world cultural and natural heritage in Paris in 1972[16], and China joined the convention in 1985. Article 1 of the convention provides cultural heritage includes artifacts, buildings and sites three categories. In 1982 issued the first national Cultural relics protection law [14], marking the beginning of the cultural heritage protection in China. Issued in 1989, Urban planning law [21], emphasizing the protection of historical and cultural heritage is a part of urban planning. In 2002 the newly revised Cultural relics protection law[14], formally established the system of protection of historical and cultural blocks. This indicated that China's historical and cultural heritage protection gradually mature and perfect. In 2005 the state councilthe opinions on strengthening the protection of cultural heritage[22] and the 2007 revision of the Cultural relics protection law[14], further clarify the need to strengthen the protection of famous historical and cultural cities, towns and villages. In 2008 the State Council promulgated the Historical and cultural city town village protection ordinance [13], marking the historical and cultural city town village protection has entered the legal system. Intangible cultural heritage law[23] promulgated in 2011 and announced the two batch of a total of 1028 national intangible cultural heritage, intangible cultural heritage has become an important part of the protection of historical and cultural resources[24].

As a kind of resources that can be protected and developed by the historical and cultural heritage, this paper thinks that it is appropriate to divide resource by the function.

\section{The Principle of Establishing a New System of Classification of Historical and Cultural Resources}

This paper argues that the historical and cultural resources in the process of classification need to follow the following principles: First, the principle of resourceoriented and market oriented, namely combine resource oriented which classified by resource itself with market oriented which from the market demand, based on the final performance of resource products in order to achieve the economic benefits. Second, the principle of combining the development and protection, to make specific development protection plans according to different resource types. In the process of resource classification should pay attention whether the classification is conducive to the future development, make sure the purpose of resource development is to make sustainable use of resources. Third, the principle of combination of simple and convenient, that classification system should be simple, clear, and at the same time to facilitate future census and evaluation, with 
operability.

\section{Construction of a New Classification System}

According to the above classification, combined with the actual situation of China's historical and cultural resources, China's historical and cultural resources can be divided into four levels: The A class, in accordance with the historical and cultural resources in the form of expression, that can be divided into 3 types of physical and chemical resources, cross type resources, spiritual resources; The $\mathrm{B}$ class, according to the endowment of resources, the historical and cultural resources are divided into 7 types, that is historical relics, near modern historian and representative buildings, ancient architecture, ancient town, precious relics, museums, intangible cultural heritage and its derivatives; The $\mathrm{C}$ class, according to functions and properties are divided into 24 small type, like ancient site of human activity, modern revolutionary site, ancient tombs, religious buildings and so on; The D class, through further refinement, historical and cultural resources are divided into 71 types. Among them, in each small category, list the representative things. Details are as follows.

Table 1 Four-level classification of historical and cultural resources

\begin{tabular}{|c|c|c|c|c|}
\hline A class & B class & C class & D class & Representative \\
\hline & & & ancient human sites & $\begin{array}{l}\text { Sanxingdui, } \\
\text { Jin Sha site }\end{array}$ \\
\hline & & & ancient capital site & Kaifeng city wall \\
\hline & & & $\begin{array}{l}\text { ancient battlefield } \\
\text { sites }\end{array}$ & Chibiancient battlefield \\
\hline & & & Military Sites & Great Wall \\
\hline & historic sites & $\begin{array}{l}\text { site of ancient } \\
\text { human activity }\end{array}$ & celebrity remains & Yue Feirelics \\
\hline & & & ruins & $\begin{array}{l}\text { Xia ruins, } \\
\text { Yin ruins }\end{array}$ \\
\hline & & & $\begin{array}{l}\text { peasant uprising } \\
\text { sites }\end{array}$ & Jintian uprising heritage \\
\hline & & & science site & $\begin{array}{l}\text { Dujiangyanirrigation } \\
\text { project }\end{array}$ \\
\hline & & & life site & $\begin{array}{l}\text { Banpo ruins, } \\
\text { Du Fu thatched cottage }\end{array}$ \\
\hline & & & traffic facilities site & $\begin{array}{l}\text { Qin Shihuang ancient } \\
\text { road }\end{array}$ \\
\hline & & $\begin{array}{l}\text { modern } \\
\text { revolutionary site }\end{array}$ & meeting place & Zunyi meeting site \\
\hline & & & uprising place & Wuchanguprising site \\
\hline & $\begin{array}{l}\text { modern historical } \\
\text { sites } \\
\text { and representative } \\
\text { buildings }\end{array}$ & $\begin{array}{l}\text { former residence of } \\
\text { celebrities }\end{array}$ & revolutionaries & $\begin{array}{l}\text { Li Dazhao's former } \\
\text { residence }\end{array}$ \\
\hline & & & social people & $\begin{array}{l}\text { Mei Lanfang's former } \\
\text { residence }\end{array}$ \\
\hline & & $\begin{array}{l}\text { representative } \\
\text { buildings }\end{array}$ & city landmark & Beijing tiananmen \\
\hline & & & $\begin{array}{l}\text { imperial } \\
\text { mausoleum }\end{array}$ & $\begin{array}{l}\text { Qin Shi Huang } \\
\text { mausoleum }\end{array}$ \\
\hline \multirow{11}{*}{$\begin{array}{l}\text { physical and chemical } \\
\text { (cultural relics and their } \\
\text { derivatives) }\end{array}$} & & ancient tomb & $\begin{array}{l}\text { celebrity } \\
\text { mausoleum }\end{array}$ & $\begin{array}{l}\text { Sun Zhong Shan } \\
\text { mausoleum }\end{array}$ \\
\hline & & & cemetery & $\begin{array}{l}\text { Shang and Zhou ancient } \\
\text { tombs }\end{array}$ \\
\hline & & & temple & White Horse temple \\
\hline & & & pagoda & Dayan pagoda \\
\hline & & $\begin{array}{l}\text { religious } \\
\text { architecture }\end{array}$ & mount rock & Jing gangjing \\
\hline & & & mural & Dunhuangmogaogrottoes \\
\hline & & & taoist temple & Beijing baiyunguan \\
\hline & & altars & nature altar temple & temple of heaven \\
\hline & ancient architecture & & $\begin{array}{l}\text { ancestor altar } \\
\text { temple }\end{array}$ & the ancestral temple \\
\hline & & & sages altar temple & Wuhoutemple \\
\hline & & & tai & Lu Tai Gang \\
\hline
\end{tabular}




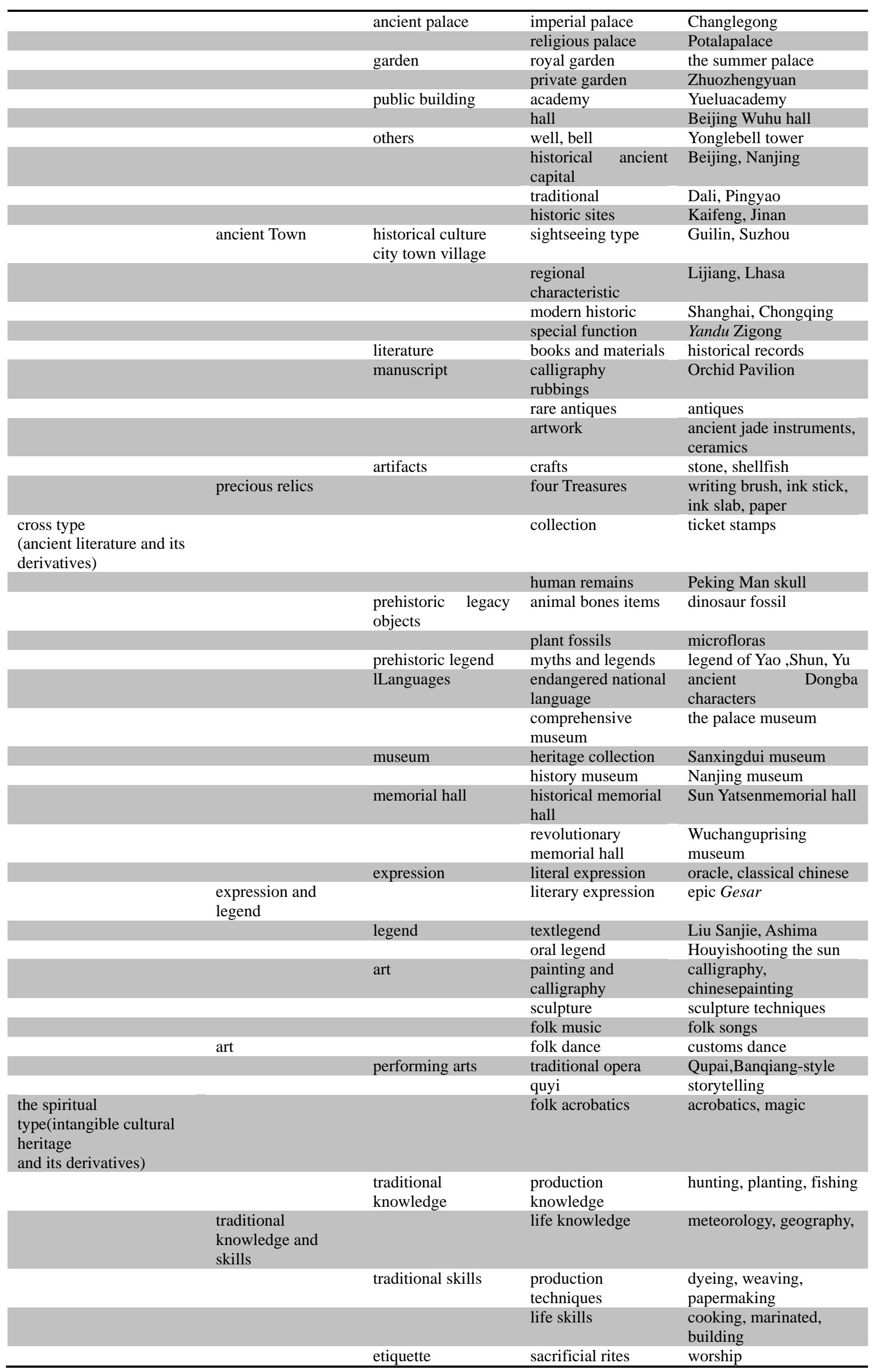




\begin{tabular}{|c|c|c|c|}
\hline & & $\begin{array}{l}\text { communicative } \\
\text { etiquette }\end{array}$ & meet, exchange, see off \\
\hline folk Activities & custom & festivals & water-sprinkling festival \\
\hline & & life etiquette & full moon, 100 days \\
\hline & $\begin{array}{l}\text { sports and } \\
\text { entertainment }\end{array}$ & sports & $\begin{array}{l}\text { Diaoyang, } \\
\text { Qianghuapao }\end{array}$ \\
\hline & & entertainment & ethnic song, dance \\
\hline
\end{tabular}

\section{Conclusion and Prospect}

\section{Demonstration of this New Classification System and Related Instructions}

Ding Jihua in tourism resource science [18] each category is not completely parallel relationship, for example,historical and cultural city tourism resources in the majority of the content can be included in the heritage tourism resources. At present, most of the research on resource classification exist problems such as classification is not clear, mixed classification standards, lead to the unclear classification boundaries and overlapping in content. The classification in Survey specification of China's tourism resources (1992)[19] and Chinese tourism geography[20]edited by Luo Zibai is relatively clear, easy to study and use. But this way of classification is too simple,just divide the resources into four or three levels in the state of their existence. At the same time, in the division of B class, for instance, the specific division of architecture and design or historic sites and buildings, there exists problems such as the content overlap between classifications, boundary is not clear, scale uncertainty, standards are not uniform. At the same time, compared with the minority high value cultural relics protection units, the scale of the historical building is large which is the main body of historical and cultural resources. From the practical work, at present, most of city only pay attention to the protection of cultural relics protection units, while ignoring the protection of historical buildings. In some of the famous historical and cultural city, a large number of valuable buildings are destroyed and removed, only isolated some cultural relic protection units. The essential reason lies in the fact that the previous classification did not separate the historical buildings, which resulted in the neglect of the historical buildings. Resulting in a number of cities in a large-scale demolition of local construction, thought that the protection of historical and cultural resources can only be protected by several cultural relics protection units, eventually led directly to the historic character of the city ceased to exist. Although in Classification, investigation and evaluation of tourism resources (GB / T 18972-2003)[10]the sites and buildings are classified as a class, but there are also the problem of the lack of classification types.

\section{Prospect}

Aiming at the existing problems of the classification, for instance, in order to avoid the problem ofthe time division and functional division standard mixed that he classification criteria are not consistent, this article unified by use function, purpose and attributes. When classifying the sites, in order to avoid unnecessary overlapping and increase the correspondence, this paper is no longer the same as the previous classification scheme, to take the time standard for the division of the history, but from the functional point of view. Separating historical buildings into one category in order to make the historical architecture better reflect the historical features and local characteristics. As most of the classification scheme is too rough, this article is appropriate to increase the category, Such as divide the precious value of artifacts into a class based on its functions and attributes. In order to make the classification name better highlight the history of resources, plus the word history or traditional in the name. At the same time, added prehistoric legacy objects, prehistoric legend, language and other types referring to the intangible cultural heritage protection in china.

Hope that through this classification, can make these precious historical and cultural resources to get enough attention and protection. 


\section{References}

[1] Zhao D, Expand the connotation of new resources: Historical and cultural resources. Journal of Humanities, 2014(4):126-128.

[2] Information on http://qstheory.cn/zxdk/2006/200601/200907/t20090708_7676.htm

[3] He S W, Classification of tourism human resources. Shanxi: Shanxi University,2007.

[4] Zhang W X, Ai P, Development Strategy of the Historical and Cultural Tourism Resources. Ecological Economy, 2007 (4):112-115.

[5] Li D H, Zhou Z L, Historical and cultural resources and urban style positioning - Taking Guangzhou as an example. Beijing: People's Publishing House, 2008.

[6] Wu M, Wang Y H, Development Strategy of Chinese historical and cultural tourism resources. The Journal of Sichuan provincial Party School, 2009(2): 83.

[7] Hao S S, Classification and Evaluation of Historical and Cultural Tourism Resource. Fujian: Fujian Normal University, 2010.

[8] Ran J J, Research on the integration of historical and cultural city resources in Yulin based on heritage protection. Shanxi: Xi'an University Of Architecture And Technology,2010.

[9] Zhao D, Research on protection and development of historical and cultural resources in digital existence -- a case study of Shanxi. Shandong: Shandong University, 2014.

[10]GB/T 18972--2003, Classification, investigation and evaluation of tourism resources.

[11]GB50357--2005, Regulations for protection of historical and cultural city.

[12]Historical and cultural cities towns and villages Protection Ordinance.

[13] Historical and cultural city town village protection planning requirements (Trial).

[14]The cultural relics protection law of the People's Republic of China.

[15]Convention on the protection of the world cultural and natural heritage.

[16]Convention on the protection of intangible cultural heritage.

[17]National Intangible Cultural Heritage List.

[18] Ding J H, Tourism resources, Shanghai, 1999.

[19] Survey specification of China's tourism resources.

[20] Luo Z B, Zhang S L, Chinese tourism geography, Tianjing, 2000.

[21]Urban planning law.

[22] The opinions on strengthening the protection of cultural heritage.

[23]Intangible Cultural Heritage Law

[24]Zhao Y, Review and Prospect of village to protect the historical and cultural city town in China.Journal of Architecture, 2012(6):12-17. 